\title{
Human cysteine dioxygenase type I (CDO-I; EC 1.13.11.20): 5' flanking region and intron-exon structure of the gene
}

\author{
D B Ramsden, A Kapadi, N J S Fitch, M J Farmer, P Bennett, A C Williams
}

\begin{abstract}
Aim-The elucidation of the structure of the 5' flanking region and the exonic organisation of the human cysteine dioxygenase type I gene.

Methods-Material for sequence studies was generated by polymerase chain reaction (PCR) methods using human genomic DNA, a cosmid clone containing the entire gene, and a commercial gene walking kit.

Results and Conclusions-The gene was found to be $\sim 12 \mathrm{~kb}$ in length and made up of five exons $(418,78,155,170$, and 731 base pairs, respectively). The immediate 5 ' flanking region did not contain the canonical TATAA box. One DNA source (Clontech promoter finder kit) contained a liver specific nuclear factor response element approximately 550 base pairs from the transcription start site, whereas a second source did not. This and other cis acting factors in the 5 ' flanking region were identified by computer analysis. The physiological significance of such elements requires detailed experimental evaluation.
\end{abstract}

(F Clin Pathol: Mol Pathol 1997;50:269-271)

Keywords: cysteine dioxygenase; liver; brain

High levels of cysteine, due to reduced levels of cysteine dioxygenase (CDO), have been claimed to be present in the brain of a patient with Hallervorden-Spatz disease (HSD), a rare neurodegenerative condition. ${ }^{1}$ Cysteine is thought to be an excitatory amino acid, acting via the NMDA receptor, ${ }^{2}$ and an excess of it may cause exocitotoxicity and thus contribute to the neuronal loss in HSD. The oxidation of cysteine by $\mathrm{CDO}$ is a one step reaction involving addition of molecular oxygen. ${ }^{3} \mathrm{CDO}$ activity is expressed not only in the brain but also in the liver (the major site of expression) ${ }^{4}$ and the kidney, ${ }^{5}$ and data from expressed sequence tags suggest that it is expressed in numerous other tissues (GenBank numbers AA097105, AA166228, AA266612, AA016488, AA345878, AA347812, AA368632). A considerable amount of information is present in the literature concerning the properties of the entity or entities responsible for CDO activity, some of which is conflicting. These data were reviewed by Ho et al. ${ }^{6}$ Whether the differences reported represent real differences or are merely methodological arte- facts is unclear. Only the enzyme mediating hepatic cytosolic activity (CDO-I) has been characterised in detail. Rat CDO-I is a single 200 residue polypeptide (molecular weight $23 \mathrm{kDa}$ ) binding one $\mathrm{Fe}^{2+}$ per molecule. Its primary sequence has been derived from cDNA. We have reported the complete sequence of the mRNA encoding human CDO- $1,{ }^{8}$ and shown that the human enzyme is encoded on chromosome 5q22-23, and the murine enzyme on chromosome 18, a region with considerable homology with human chromosome $5 .{ }^{9}$ Here, following a study using a combination of polymerase chain reaction (PCR) techniques and DNA base sequencing, we report: that the gene is in excess of $12 \mathrm{~kb}$ and contains five exons; the base sequence of $-70 \%$ of the gene and its adjacent 5 ' flanking region; and the results of computer analyses of 608 base pair of the 5 ' flanking region.

\section{Material and methods}

TEMPLATES FOR PCR AMPLIFICATIONS

Three sources of DNA to act as templates for PCR amplification were used: (a) genomic DNA (male caucasian) extracted from white blood cells by the method of Sykes ${ }^{10}$; (b) a clone from a cosmid library, identified as described previously"; and (c) a "promoter finder" library (Clontech, Cambridge Bioscience, Cambridge, UK).

PCR AMPLIFICATIONS

Using oligomeric primers (18-21 mers) synthesised by Alta Bioscience (Birmingham, UK) and designed with reference to the CDO-I cDNA reported previously, ${ }^{8}$ a series of PCR amplifications was carried out using genomic DNA as the template and a relatively short range amplification protocol to map exonintron boundaries approximately. The amplification protocol was: denaturation at $99^{\circ} \mathrm{C}$ for five minutes, equilibrium at $72^{\circ} \mathrm{C}$ for five minutes, followed by addition of Taq polymerase, and 30 cycles of $95^{\circ} \mathrm{C}$ for 30 seconds, $55^{\circ} \mathrm{C}$ for 30 seconds, and $72^{\circ} \mathrm{C}$ for one minute.

Amplicons that were the same size as that anticipated if cDNA was the template, were considered as entirely exonic. Amplicons that were larger were considered as containing intronic material. If no amplicon was produced, it was considered likely that either the primer lay across an exon-intron boundary or the intron between the primers was of such a size as to prevent amplification with this protocol.

Potentially large introns were investigated by a long range PCR strategy ${ }^{11}$ using cosmid DNA 


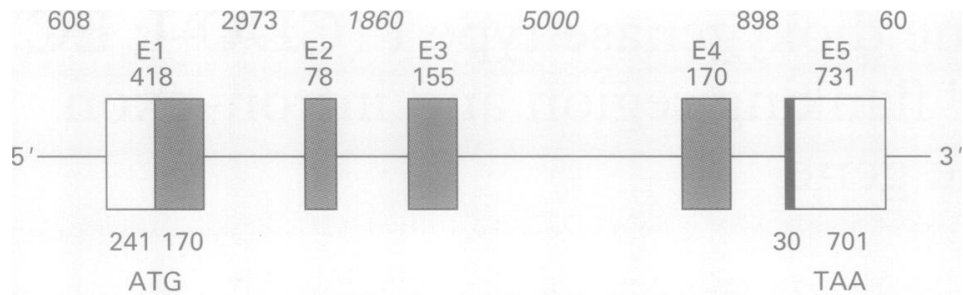

(1)

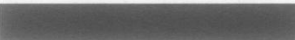

Figure 1 Exonic structure of the human CDO-I gene. Exons (E) shown as rectangles with introns and flanking regions shown as lines. Open rectangles denote untranslated exons and shaded rectangles denote translated exons or part exons. The sizes (base pairs) of complete exons are above the rectangle, and the parts untranslated and translated below. The size of introns and flanking regions form the uppermost layer of numbers, with italics denoting estimated sizes of introns that were not fully sequenced. The parts of the gene for which sequence data have been deposited in GenBank are denoted by the bars at the bottom of the figure.

as the initial template and then genomic DNA, commercial Taq/proofreading enzyme mixtures, long primers (24-28 mers) with melting points of greater than $60^{\circ} \mathrm{C}$, and an extension time of five minutes for single introns and 10 minutes for the whole gene.

The $5^{\prime}$ flanking region of the gene was amplified using the promoter finder kit from Clontech and two 28 mer primers based on the sequence of the $5^{\prime}$ end of CDO-I cDNA. The amplifications were carried out according to the supplier's protocol, using XL-Tth DNA polymerase (Perkin Elmer, Warrington, UK).

\section{CLONING AND SEQUENCING}

Small amplicons $(<2 \mathrm{~kb})$ were cloned into TA cloning vector (Invitrogen, Leek, the Netherlands) and large amplicons were cloned into pMOS Blue (Amersham Life Sciences, Little Chalfont, UK). ${ }^{11}$ Automated PCR sequencing was carried out using an $\mathrm{ABI} 373$ sequencer (Applied Biosystems, Warrington, UK). Manual sequencing was performed using the fMol cycle sequencing kit (Promega, Southampton, UK).

Table 1 Vertebrate transcription regulatory elements identified by MatInspector and TFSearch routines

\begin{tabular}{lll}
\hline Element & CoresSequence & Position (Strand) \\
\hline Part1 & MatInspector & Core similarity $=1 ;$ Matrix similarity $>0.9$ \\
& TFSearch & Score $>88$ \\
AP1 & tgac & $-55(+)$ \\
cMyb & gttg & $-71(+)$ \\
deltaEF1 & acct & $-528(+)$ \\
GATA1 02 & gata & $-506(+)$ \\
HFH2/HNF3B & tatt & $-564(-)$ \\
IK2 & ggga & $-188(+)$ \\
MZF1 & gggg & $-398(-) ;-364(-) ;-292(+) ;-128(-)$ \\
NKX2.5 & aagt & $-252(+)$ \\
sp1 & ggcg & $-124(-)$ \\
vMy & bgcaa & $-283(-) ;-72(-)$ \\
& & \\
Part 2 & MatInspector & Core similarity $=1 ;$ Matrix similarity $>0.9$ \\
& TFSearch & Score $>85$ \\
Lyf1 & ggga & $-188(+)$ \\
MZF1 & gggg & $-171(+) ;-162(+)$ \\
NfkB50 & gggg & $-128(-)$ \\
Part 3 & Some elements listed & using MatInspector criteria of core \\
& similarity $=1 ;$ Matrix & similarity $>0.85$, not identified by \\
AHRARNT & TFSearch & $-226(-) ;-151(+)$ \\
Barbie & cgtg & $-395(-) ;-390(-) ;-113(-)$ \\
CDPCR3HD & aaag & $-461(+)$ \\
CETSIP54 & gatc & $-207(+)$ \\
CREB & cgga & $-370(-)$ \\
\hline & tgac &
\end{tabular}

\section{STRUCTURAL ANALYSIS}

The structure of the $5^{\prime}$ flanking region of the gene was analysed to detect the presence of potential regulatory elements using two software packages available via the Internet: MatInspector, via http://www.gsf.de/biodv/ matinspector.htm ${ }^{12}$ and TFSearch, via http:// www.genome.ad.jp/SIT/SIT.html.

Results

In the initial analysis, 30 separate PCRs, with genomic DNA as template, were carried out 흠 using primer pairs that were between 200 and $\frac{}{5}$ 400 base pairs apart on the cDNA and which $\stackrel{\mathbb{\Omega}}{\Omega}$ spanned the entire length of the cDNA. Before sequencing the amplicons, the initial results $\overrightarrow{0}$ suggested that the gene was some $6 \mathrm{~kb}$ in length and contained three introns of approxi- $\vec{\omega}$ mately $2 \mathrm{~kb}, 2 \mathrm{~kb}$, and $1 \mathrm{~kb}$. On sequencing the amplicons, it was clear that neither of the $2 \mathrm{~kb}$ ? introns represented an accurate picture of the $f$ gene. The amplicons obtained contained ir cDNA sequence at the $3^{\prime}$ ends of introns but $\mathrm{O}$ not at the $5^{\prime}$ ends, suggesting that the actual introns were much bigger than $2 \mathrm{~kb}$. The final intron of $\sim 1 \mathrm{~kb}$ was positioned accurately $\vec{O}$ within the cDNA, because continuous sequence was obtained from cDNA at its $5^{\prime}$ end, then through the entire length of the intron and into cDNA again.

To clarify the intronic structure of the remainder of the gene a second round of amplifications was carried out using cosmid DNA as template and a long range PCR strategy. This revealed that the gene contained a total of four, not three, introns with lengths of $\stackrel{\mathbb{Q}}{\circledR}$ approximately $2 \mathrm{~kb}, 2.5 \mathrm{~kb}, 5 \mathrm{~kb}$, and $1 \mathrm{~kb}$. $\overrightarrow{\mathrm{O}}$ Sequencing of the amplicons accurately posi- 3 tioned the introns within the cDNA sequence. All introns have canonical start and stop? sequences. The structure of the gene is shown in fig 1, with the portions sequenced and the results submitted to GenBank indicated. Avail- 3 able sequence data covers approximately $70 \%$ of the gene.

Using the promoter finder kit an amplicon of $\mathrm{O}$ $\sim 1 \mathrm{~kb}$ was generated that, on sequencing, was shown to contain 608 base pairs of 5' flanking region. A second amplicon of approximately $3 \mathrm{~kb}$ was shown to contain $2.5 \mathrm{~kb}$ of 3 ' flanking o sequence.

Analysis of the 5' flanking sequence using two computer packages identified more than 100 sites each (MatInspector, 106; TFSearch, 127). The two packages gave somewhat differ- $\mathbb{D}$ ent results, presumably because of the differ-? ences in the algorithms, although some elements were identified by both. To concentrate $\vec{D}$ on what may be the physiologically most $\frac{\Omega}{\mathbb{D}}$ important sites, strict criteria were used to $\stackrel{2}{2}$ reduce the numbers. Ones that were identified by both packages using higher criteria for 0 selection than those that form the default criteria, are highlighted in part 1 of table $1 . \overline{0}$ Elements identified with somewhat less cer-? tainty are shown in subsequent sections. The most important features are: (a) the absence of a canonical TATAA box, although an element with some sequence homology to such a box is present at -37 to -42 base pairs from the 


$\begin{array}{llllll}-608 & & & & \text { CGACGGCC } \\ -600 & \text { CGGGCTGGTA } & \text { AAAAATATGT } & \text { GTGTGTGTAT } & \text { ACTTAAATAA } & \text { ATATATATAT } \\ -550 & \text { ATAAAGTCTT } & \text { GGACTTATT } & \text { TCACCTAGCC } & \text { TGGGGCATAT } & \text { CGTGGATAGT } \\ -500 & \text { TTCAATCGAC } & \text { AAAACAGGCA } & \text { CTCTCTGGCC } & \text { TAGGAGTGGA } & \text { ATCCATCCTC } \\ -450 & \text { AATTTTCGCA } & \text { GGCTCCTCAC } & \text { AATTCTCTAT } & \text { TTGGAAGAAG } & \text { TGTCCCTCTC } \\ -400 & \text { CTCCCCTTT } & \text { CTTTTCCTC } & \text { TTTACTCAGC } & \text { GTCAGTCCC } & \text { GCAGCCATCT } \\ -350 & \text { CCTCCGACCC } & \text { TTTTTGTCTA } & \text { CGTCCCAGCG } & \text { TCGCGAACCA } & \text { CAGCGGCGGA } \\ -300 & \text { GGTGGAGCGG } & \text { GGAGAGGCGT } & \text { TAGGCCGGGC } & \text { GGCTAAAACG } & \text { CGCCGTTAAA } \\ -250 & \text { GTGGGGGAGA } & \text { GATTGCGCGG } & \text { AGCCCACGCG } & \text { ATCCCTGGGA } & \text { CGCCGGAGAC } \\ -200 & \text { AACGGGGCTC } & \text { TTGGGAAGGC } & \text { GCGGAGCCCG } & \text { GGGAAGCCGG } & \text { GGATGTGCGC } \\ -150 & \text { GTGAGCCGTG } & \text { CCCGCAGGGT } & \text { CTCCCCGCCT } & \text { CCGCCACCTT } & \text { TCTTGGGTGG } \\ -100 & \text { CTCTCCGCCT } & \text { CGTCCTCCCT } & \text { CCGAGGGCCG } & \text { TTGGTACATT } & \text { CCTAGTGACT } \\ -50 & \text { CCAAGCGCTT } & \text { AAAAGGGGCC } & \text { CGGGAGGGTG } & \text { AACCCCACAG } & \text { ATCTGAACCT }-1\end{array}$

Figure 2 Sequence of the 5' flanking region. The two underlined bases (-561 and -562) generate the HFH2/HNF3B site not seen in some templates.

transcription start site; and (b) the presence of $\mathrm{AP} 1$, c and $\mathrm{v}$ Myb, MZF1, NF B, Ikaross2, NKX2.5, and HFH2/HNF-3B elements. In addition, the MatInspector package identified potential AHRARNT, BARBIE, CREB, and Delta Ef1 elements, all of which may warrant further experimental exploration.

Using the sequence data obtained from the promoter finder template we devised primers to amplify the same region using the cosmid as template. One important difference was seen between the two sequences-the cosmid template had two bases (AA) absent (promoter finder, cttaaatAAatatat; cosmid, cttaaatatatat). This deletion destroyed the HFH2/HNF-3B response element. Immediately $3^{\prime}$ to this site are repeated AT units, which are absent in the rat sequence. These repeat units may also form a polymorphic site. The sequence of the $5^{\prime}$ flanking region is shown in fig 2 .

\section{Discussion}

The gene encoding human $\mathrm{CDO}$ at position $5 q 21-23$ is $\sim 12 \mathrm{~kb}$ in size and contains five exons. The human gene has a very similar exon-intron organisation to that of the rat gene, described by Tsuboyama et al. ${ }^{13}$ It lacks a canonical TATAA box in its 5' flanking region adjacent to the putative transcription start site although it, like the rat gene, possesses a related element (TTAAA).

Previous workers have shown that upregulation of the enzymic activity occurs in liver following in vivo administration of cysteine in the rat. ${ }^{14}$ How such regulation is effected is unclear as yet. It could indicate the presence of an as yet undescribed nuclear receptor for cysteine (so called orphan receptors for which no endogenous ligands are well recognised) or cysteine may alter the redox state within the cell and influence transcription via $A P 1$ and NF-Kappa B, which respond to several factors including redox state. ${ }^{15}$ Both AP1 and NFKappa B were identified here. The presence of a hepatocyte specific response element in the human gene was thought initially to account for the fact that the liver expresses high levels of CDO activity. However, the absence of this element in a second template, and in sequence data from Japanese workers (GenBank D85778S1) suggest that this may be a polymorphic site. Whether relatively high liver expression occurs independently of the presence or absence of the $\mathrm{HFH} 2 / \mathrm{HNF}-3 \mathrm{~B}$ site remains to be determined. Because all the regulatory elements have been identified by computer search only, further work is required to elucidate the physiological importance of these sites and to identify the factors interacting with them in the liver and other tissues.

1 Perry TL, Norman MH, Young VS, Whiting S, Crichton JU, Hansen S, et al. Hallervorden-Spatz disease: cysteine accumulation and cysteine dioxygenase deficiency in the globus pallidus. Ann Neurol 1985;18:482-9.

2 Olney JW, Zorumski C, Price MT, Labruyere JL. L-cysteine, a bicarbonate-sensitive endogenous excitotoxin. Science 1990;248:596-9.

3 Lombardini JB, Singer TP, Boyer PD. Cysteine oxygenase II. Studies on the mechanism of the reaction with oxygen. f Biol Chem 1969;244:1172-5.

4 Yamaguchi K, Sakakibara S, Asamizu J, Ueda I. Induction and activation of in vivo activity of cysteine oxidase of rat liver. II. The measurement of cysteine metabolism in vivo and the activation of in vivo activity of cysteine oxidase. Biochim Biophys Acta 1973;297:48-59.

5 Stipanuk MH, de la Rosa J, Hirschberger LL. Catabolism of cyst(e)ine by rat renal cortical tubules. $\mathcal{F}$ Nutrit $1990 ; 120$. 450-8.

6 Ho SL, McCann KP, Bennett P, Kapadi AL, Waring RH, Ramsden DB, et al. The molecular biology of xenobotic Ramsden DB, et al. The molecular biology of xenobotic enzymes and the predisposition to

7 Hosokawa Y, Matsumoto A, Oka J, Itakura H, Yamaguch $\mathrm{K}$. Isolation and characterisation of a CDNA for rat liver cysteine dioxygenase. Biochem Biophys Res Commun 1991 168:473-8.

8 McCann KP, Akbari MT, Williams AC, Ramsden DB. Human cysteine dioxygenase type-I: primary structure derived from base sequencing of CDNA. Biochim Biophys Acta 1994;1209:107-10.

9 Jeremiah S, McKann KP, Williams AC, Ramsden DB, Pilz AJ, et al. Chromosomal localisation of genes coding for human and murine liver cytosolic cysteine dioxygenase. Ann Hum Genet 1996;60:29-33.

10 Sykes B. DNA in heritable disease. Lancet 1983;ii:787-8.

11 Bennett P, Ramsden DB, Williams AC. Complete structural characterization of the human aryl hydrocarbon receptor gene. $\mathcal{f}$ Clin Pathol: Mol Pathol 1996;49:M12-16.

12 Quandt K, Frech K, Karas H, Wingender E, Werner T. MatInd and MatInspector-new fast and versatile tools for MatInd and MatInspector-new fast and versatile tools for detection of consensus matches in nucleo
data. Nucleic Acids Res 1995;23:4878-84.

13 Tsuboyama N, Hosokawa Y, Totani M, Oka J, Matsumoto A, Koide T, et al. Structural organisation and tissue-specific expression of the gene encoding rat cysteine dioxygenase. Gene 1996;181:161-5.

14 Yamaguchi K, Sakakibara S, Koga K, Ueda I. Induction and activation of cysteine oxidase of rat liver. Biochim Biophys Acta 1971;237:502-12.

15 Meyer $\mathrm{M}$, Schreck $\mathrm{R}$, Baeuerle PA. $\mathrm{H}_{2} \mathrm{O}_{2}$ and antioxidants have opposite effects on activation of NF B and AP-1 in intact cells: AP-1 as secondary antioxidant-responsive factor. $E M B O \mathcal{f} 1993 ; 12: 2005-15$. 